\section{Increasing the Sugar Concentration in Tomato Fruit Juice by Coiling Wire Around Plant Stems}

\author{
Ken Takahata and Hiroyuki Miura ${ }^{1}$
}

AdDitional INDEX wORDs. basal wire coiling, impeded sap flow, root growth, Solanum lycopersicum, soluble solids

SUMMARY. Sugar concentration is an important aspect of fruit quality in tomato (Solanum lycopersicum) production. Salt and water stresses have been reported to increase the sugar concentration of fruit. Coiling wire around the lower part of the stems to reduce the capacity of xylem to transport water to shoot would result in low shoot moisture condition and increase the sugar concentration of fruit like salt and water stresses. The objective of this study was to determine whether a prototypic method of wire coiling increases the sugar concentration of fruit. Bonsai wire was coiled around the stems of seedlings in February in a greenhouse between the cotyledon node and the first leaf node. Eleven days after treatment (DAT), the stem diameters immediately above the wire coils were markedly greater in treated plants compared with the corresponding stem regions of control plants. The stems of treated plants were less elongated and developed fewer nodes at 39 and 51 DAT than the control plants. Marketable fruit harvested from the first to third trusses of the treated plants in April to May had average weights that were $49 \%$ to $89 \%$ of the weights of fruit from control plants. The juice of fruit from the first to third trusses in the treated plants had soluble solids concentrations of $116 \%$ to $120 \%$, sucrose concentrations of $263 \%$ to $483 \%$, and fructose and glucose concentrations of $135 \%$ to $155 \%$, compared with juice from corresponding control fruit. At 112 DAT, the shoots and roots of treated plants had weights that were $58 \%$ and $32 \%$ of those of control plants, respectively. The basal wire coiling treatment increased the sugar and soluble solids concentrations of tomato fruit juice; however, further investigation will be necessary before the technique can be adopted for practical use.

$\mathrm{H}$ igh concentration of soluble solids such as sugar is an important element of tomato fruit quality. The sugar or dry matter concentration of tomato fruit varied between cultivars (Simandle et al., 1966), but could be increased by salt or water stress (Ehret and Ho, 1986; Johnstone et al., 2005; Rudich et al., 1977; Saito et al., 2009; Sakamoto et al., 1999). However, such treatments require proper equipment and techniques, and in practice are neither easy nor simple. Coiling wire by hand around the lower parts of the stems would result in impeded translocation of photosynthates to the roots, which suppresses root growth and water absorption by the roots, like the treatment of salt or water stress. This also impeded the transport of water to the upper parts of the shoots, which accelerates a reduction in the moisture

Department of Agriculture, Tokyo University of Agriculture, Atsugi 234-0034, Japan

We sincerely thank Naohisa Shimoguchi, Juri Ishizaki, Anna Niikura, Taichi Sugiyama, Norie Urabe, Yasumasa Shimoshita, Sachiko Hoshiyama, Satoshi Obana, and Toshihide Fuchigami for their cooperation in this experiment.

${ }^{1}$ Corresponding author. E-mail: miurahvg@nifty. com. content of the shoot. In this article, we studied whether a prototypic method called "basal wire coiling" could increase the sugar concentration in tomato fruit juice.

\section{Materials and methods}

Plant culture. Tomato plants ('Momotaro 8'; Takii \& Co., Kyoto, Japan) were cultured in a glasshouse equipped with a ventilation fan and a heater (to maintain temperature between 14 and $25^{\circ} \mathrm{C}$ ) from 24 Nov. 2008 to 1 June 2009. Cell trays (Landmark Plastic Corp., Akron, $\mathrm{OH}$ ) with 128 cells were divided into four smaller trays with 32 cells, and the cells were filled with a germination soil mix containing $150 \mathrm{mg} \cdot \mathrm{L}^{-1}$ nitrogen $(\mathrm{N})$, $437 \mathrm{mg} \cdot \mathrm{L}^{-1}$ phosphorus $(\mathrm{P})$, and 125 $\mathrm{mg} \cdot \mathrm{L}^{-1}$ potassium $(\mathrm{K})$ (Yosaku N-150; Jcam Agri. Co., Tokyo, Japan) before sowing the tomato seeds. A $6 \mathrm{~N}-$ $4.4 \mathrm{P}-4.2 \mathrm{~K}$ liquid fertilizer (Hyponex 6-10-5; Hyponex Japan Co., Osaka, Japan) was diluted 3000 times and supplied to the seedlings once every day after the emergence of the first true leaf [ $20 \mathrm{~d}$ after sowing (DAS)]. When the fourth leaf began to emerge (37 DAS), seedlings were transferred to $7.5-\mathrm{cm}$-diameter plastic pots filled with another soil mix $\left[0.4 \mathrm{~g} \cdot \mathrm{kg}^{-1} \mathrm{~N}\right.$, $0.8 \mathrm{~g} \cdot \mathrm{kg}^{-1} \mathrm{P}$, and $0.5 \mathrm{~g} \cdot \mathrm{kg}^{-1} \mathrm{~K}$ (Kureha Engei Baido; Kureha Corp., Tokyo, Japan)]. This soil mix was used in all subsequent treatments.

The plants were repotted in $10.5-\mathrm{cm}$-diameter plastic pots when seven to eight leaves had emerged ( 57 DAS), and then 11 plants were coiled with wire immediately before the first flower of the first truss bloomed [9 Feb. (77 DAS)]. These plants and 11 untreated control plants were transferred to larger plastic pots $(40 \mathrm{~cm}$ upper diameter, $34 \mathrm{~cm}$ lower diameter, and $30 \mathrm{~cm}$ height) filled with $27 \mathrm{~L}$ of soil. The 22 plants were arranged in two rows with control and treated plants alternating, and with two extra plants at both ends of each row. One treated plant whose growth became determinate during the experiment was excluded from the analysis.

The plants were guided with strings hanging from the ceiling for single-stem training. A solution of 4chlorophenoxyacetic acid (0.0015\%) was sprayed onto the first six trusses to enhance fruit setting. Each pot was supplied with 1 L of a 1000-fold dilution of the liquid fertilizer once in every $10 \mathrm{~d}$ starting on 99 DAS, when the average diameter of the largest fruit of the first truss reached 2 to $3 \mathrm{~cm}$.

\begin{tabular}{llll}
\hline $\begin{array}{l}\text { Units } \\
\text { To convert U.S. to SI, } \\
\text { multiply by }\end{array}$ & U.S. unit & SI unit & $\begin{array}{l}\text { To convert SI to U.S., } \\
\text { multiply by }\end{array}$ \\
\hline 29.5735 & $\mathrm{fl} \mathrm{oz}$ & $\mathrm{mL}$ & 0.0338 \\
3.7854 & gal & $\mathrm{L}$ & 0.2642 \\
2.54 & inch(es $)$ & $\mathrm{cm}$ & 0.3937 \\
25.4 & inch $(\mathrm{es})$ & $\mathrm{mm}$ & 0.0394 \\
1 & micron & $\mu \mathrm{m}$ & 1 \\
28.3495 & $\mathrm{oz}$ & $\mathrm{g}$ & 0.0353 \\
1.7300 & $\mathrm{oz} / \mathrm{inch}^{3}$ & $\mathrm{~g} \cdot \mathrm{cm}^{-3}$ & 0.5780 \\
62.5000 & $\mathrm{oz} / \mathrm{lb}$ & $\mathrm{g} \cdot \mathrm{kg}^{-1}$ & 0.0160 \\
1 & $\mathrm{ppm}$ & $\mathrm{mg} \cdot \mathrm{L}^{-1}$ & 1 \\
$\left({ }^{\circ} \mathrm{F}-32\right) \div 1.8$ & ${ }^{\circ} \mathrm{F}$ & ${ }^{\circ} \mathrm{C}$ & $\left({ }^{\circ} \mathrm{C} \times 1.8\right)+32$
\end{tabular}


Adjustment of watering QUANTITY. After the final repotting, soil moisture probes (EC-5; Decagon Devices, Pullman, WA) were inserted into the pots of four treated plants and four control plants. The probe sensors were placed 15 to $20 \mathrm{~cm}$ under the soil surface and $6 \mathrm{~cm}$ away from the plant stems. The soil moisture values (nominal volumetric water content percentage) were read at $\approx 1000$ HR each day. Using $19 \%$ moisture as the target value after watering, an amount of water corresponding to the difference from the average measurement was supplied to each pot just after the reading (maximum $1250 \mathrm{~mL}$ ). Plants were watered each day except those days when liquid fertilizer was supplied. From the beginning of April onward, the appearance of the soil surface was assessed in the afternoon of sunny days, and additional water $(250$ or $500 \mathrm{~mL}$ ) was added to dry pots. A larger number of untreated control plants were supplied with additional water (usually $500 \mathrm{~mL}$ ) than treated plants. The daily soil moisture percentages for treatment and control, obtained from February to May, did not show significant differences.

Basal WIRE COILING. On 9 Feb., the stems of 11 plants were manually wound with aluminum bonsai wire (1.0 $\mathrm{mm}$ diameter). The wire was wound upward with 20 turns, beginning $\mathrm{l} \mathrm{cm}$ above the cotyledonary node. No spaces were left between the coils, and the wires were not tightened with a tool.

EVALUATION OF PLANT GROWTH. Stem diameter, stem length, and the number of nodes with unfolded leaves $(5 \mathrm{~cm}$ or larger) were examined every $10 \mathrm{~d}$ until mid-May [92 d after treatment (DAT)]. At that stage, many fruit developing on the third trusses had already been harvested. The stem diameters were measured above the soil and immediately above the wire in treated plants and at corresponding locations for the control plants. Stem lengths were measured until late April when the stems were no longer erect, making accurate evaluation difficult.

On 1 June (112 DAT and l week after harvesting the third trusses), the aboveground parts of the plants were divided into unripe fruit $3 \mathrm{~cm}$ or larger in diameter, and stems and leaves including small fruit under $3 \mathrm{~cm}$ in diameter (mostly on the fifth or younger trusses). The fresh weights of these plant parts were measured. Roots from six each of the control and treated plants were rinsed thoroughly in water in a vat $(110 \mathrm{~L})$ to remove the soil mixture; the water was drained through a fine net to prevent loss of broken roots. The intact and broken roots from each plant were combined and blotted dry with paper towels before measuring the fresh weight.

EXAMINATION OF HARVESTED FRUIT. Fruit were harvested successively from the first to sixth trusses when they were nearly fully colored. Fruit that were malformed, cracked, or had blossom-end rot were removed from the first to third trusses and excluded from the analysis. Calyxes were removed and the weight and diameter/height ratio were measured for marketable fruit. The fruit were covered with water, and the water displacement values were used in the density calculations (grams per cubic centimeter). Double-layered gauze was used to squeeze the fruit to measure the soluble solids concentration with a digital refractometer (PR-101 $\alpha$; Atago Co., Tokyo, Japan). Supernatants were obtained by centrifugation $\left(3000 g_{n}, 10^{\circ} \mathrm{C}, 15 \mathrm{~min}\right)$ and stored at $-20^{\circ} \mathrm{C}$.

ANALYSES OF SUGARS AND ACIDS. A fixed amount of raffinose was added as an internal standard to each thawed sample that was then neutralized with a $1 \%$ sodium hydroxide solution and filtered through a membrane filter $(0.45 \mu \mathrm{m})$. The filtrate was used for the sugar analyses. Another series of thawed samples was filtered and used for the organic acid analyses.

The liquid chromatography system (Shimadzu Co., Kyoto, Japan) consisted of a controller (model SCL10A VP), a pump (LC-10AD), a column oven (CTO-20A), and a data processor (C-R8A). Sugars were analyzed with a differential refractometer (Detector Shodex RI-101; Showa Denko K.K., Kanagawa, Japan) and a ligand exchange column (Shodex Sugar KS-801; Showa Denko K.K.) eluted with water $\left(80^{\circ} \mathrm{C}, 0.2 \mathrm{~mL} \cdot \mathrm{min}^{-1}\right.$, $15 \mathrm{~min})$. Organic acids were analyzed with a spectrophotometer (wavelength $210 \mathrm{~nm}$, Detector SPD-10AV, Shimadzu Co.) and two ion exclusion columns (Shodex RSpak KC-811, Showa Denko K.K.) eluted with $1 \mathrm{~mm}$ perchloric acid $\left(50{ }^{\circ} \mathrm{C}, 1.0 \mathrm{~mL} \cdot \mathrm{min}^{-1}\right.$, $25 \mathrm{~min}$ ).
Data ANalysis AND STATISTiCs. All data were analyzed using Student's $t$ test to determine differences between the treatment means and the control means.

\section{Results and discussion}

Plant growth. Stem diameters below the first leaves and immediately above the coiled wires markedly increased by 11 DAT and had reached $178 \%$ of those of the corresponding stem parts in the control plants by 71 DAT (Fig. 1A). Noel (1970), Richardson (1975), and Sitton (1949) reported that girdling (i.e., removing the bark including the phloem) of tree trunks or branches resulted in swelling immediately above the treatment. Mason and Maskell (1928) girdled cotton (Gossypium barbadense) plant stems and found an increased amount of sugar in the stem above the treatment. Greene (1937) girdled an apple (Malus $\times$ domestica) branch and observed increased amounts of sugar in the spurs. These observations suggest that the stem swelling above the wire coils in our experiment may resulted from the accumulation of carbohydrates, auxins (Noel, 1970), etc., because of impeded downward translocation of the sieve tube sap. As occurs with girdling, basal wire coiling activated the development of wounded and healed tissue and cambial cell division more intensely than in stems below the treatment or in nontreated plants. In contrast, the average stem diameter at the ground level, which is presumed to be closely related to the volume of root growth because of the proximity to the roots, was smaller in treated plants than in control plants by 39 DAT. Furthermore, the average stem length (Fig. 1B) was shorter in the treated plants than in the control plants after 39 DAT, and the number of nodes with unfolded leaves (Fig. 1C) were lower in the treated plants than in the control plants by 51 DAT. As stated above, among these effects of the basal coiling treatment, the swelling above the wire coil was remarkable as to external appearance and degree.

Table 1 shows the effects of basal wire coiling on the growth of tomato unripe fruit, shoots, and roots at the completion of the experiment (112 DAT). There were no differences in the numbers or weights of unripe fruit $3 \mathrm{~cm}$ or more in diameter (mostly in 

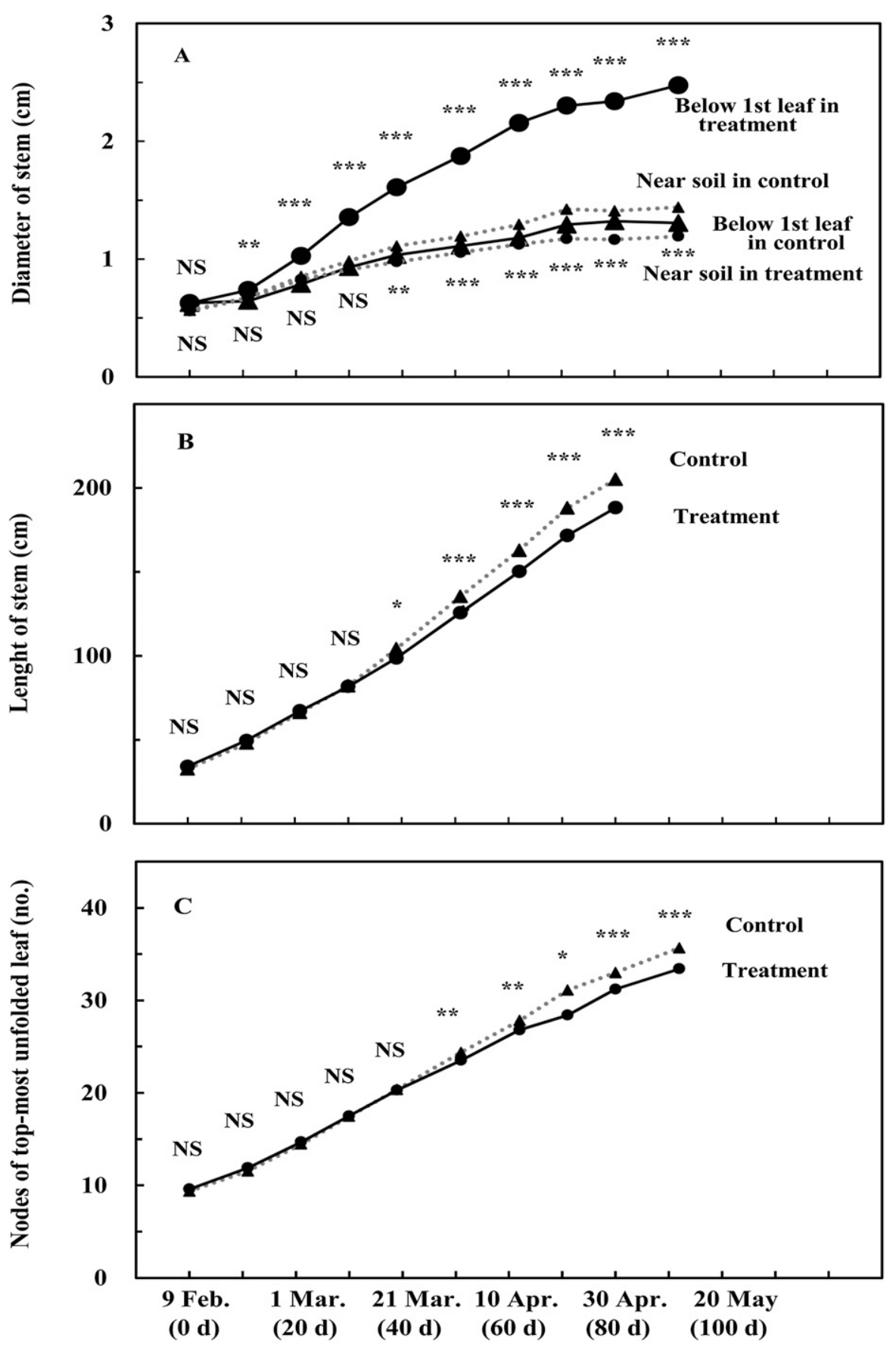

Fig. 1. Effects of basal wire coiling treatment on tomato stem thickening below the first leaf and near the soil (A), stem elongation (B), and leaf unfolding (C). The stem diameter below the first leaf in the treatment is that immediately above the wire coils. Days after the beginning of treatment are shown in parentheses below the dates; $\mathrm{NS},{ }^{*}, * *$, and $* * *$ indicate nonsignificant and significant differences by Student's $t$ test at $P=0.05, P=0.05, P=0.01$, and $P=0.001$, respectively; $1 \mathrm{~cm}=0.3937$ inch.

the fifth or younger trusses) between the treated plants and the control plants. However, stem and leaf weights (including fruit smaller than $3 \mathrm{~cm}$ in diameter) were lower (58\% of control) in the treated plants compared with the control plants. The fresh weights of roots from the treated plants were $32 \%$ of those of the control plants. Therefore, at the completion of the experiment, the growthsuppressing effects of the basal wire coiling treatment were pronounced in the roots. Impeded photosynthate translocation to the roots by basal wire coiling was responsible for the suppression of root growth.

Days to HARVEST, NUMBER, WEIGHT, SHAPE, AND DENSITY OF THE FRUIT. There were no significant differences between treated and control plants in the number of days to harvest of the marketable fruit from the first to third trusses (Table 2). The number of days to harvest for the first truss was 70 DAT, whereas the stem swelling immediately above the coil and the suppression of stem elongation by the treatment occurred by 11 DAT (Fig. 1A) and 39 DAT (Fig. 1B), respectively. Therefore, the growth of the first to third trusses was presumably affected by the treatment. The marketable fruit numbers were lower in the first trusses of the treated plants than in the control plants, but there were no significant differences in fruit numbers in the second and third trusses. The total numbers of harvested fruit, including those with blemishes, mostly blossom-end rot (physiological disorder induced by water stress), were similar between treated and control plants. The total number of fruit for treated plants was $2.1,3.3$, and 3.2 in the first, second, and third trusses, respectively, whereas the average total number of fruit for the control plants were $2.5,3.0$, and 3.7. There were no differences in the numbers of fruit with blemishes in each truss between treated and control plants. The average weights of marketable fruit from the first trusses did not differ significantly between treated and control plants, but fruit from the second and third trusses of the treated plants weighed less $(73 \%$ and $49 \%$, respectively) than those from the control plants. Ehret and Ho (1986), Saito et al. (2009), and Sakamoto et al. (1999) also reported the fruit size decreases by salt stress. The fruit diameter/height ratios indicating fruit shape were lower in the treated vs. control plants only in the third trusses. Fruit densities did not differ in the second trusses between control and treated plants but were higher in the first and third trusses of treated plants. The small numbers of marketable fruit in the first to third trusses combined were likely because of the large variations in soil moisture in individual pots from morning to afternoon, and to the low humidity in the greenhouse, which led to poor fruit 
set and the development of blossomend rot. The reduced fruit weight in the treated plants may have resulted from the reduced amounts of water absorbed by the roots and moved to the shoots. In summary, the effects of basal wire coiling were seen in the decreased fruit weights. In Japan, small tomato fruit with high sugar content by salt stress, etc. is being sold at a high price. If the fruit grown by the basal wire coiling treatment is valued at high price, the yield loss may be offset.

SUGAR AND ORGANIC ACID CONCENTRATIONS OF FRUIT JUICE. Table 3 shows the effects of basal wire

Table 1. Effects of basal wire coiling treatment on the growth of unripe tomato fruit, shoots, and roots at the end of the experiment.

\begin{tabular}{|c|c|c|c|c|}
\hline \multirow[b]{2}{*}{ Plot } & \multirow{2}{*}{$\frac{\frac{\text { Unripe fruit }^{\mathrm{z}}}{\text { Total fruit }}}{\text { (no./plant) }}$} & $\frac{\text { Shoot }^{\mathrm{y}}}{\text { Total fresh wt }}$ & \multicolumn{2}{|c|}{$\frac{\text { Root }}{\text { Fresh wt }}$} \\
\hline & & \multicolumn{3}{|c|}{$(\mathrm{g} / \text { plant })^{\mathrm{x}}$} \\
\hline Control & 10.1 & 1000.7 & 1672.9 & 418.6 \\
\hline Treatment & 8.2 & 739.9 & 973.8 & 135.3 \\
\hline & NS & NS & $* * *$ & $* * *$ \\
\hline
\end{tabular}

Table 2. Effects of basal wire coiling treatment on days to harvest, number, weight, and shape of marketable tomato fruit.

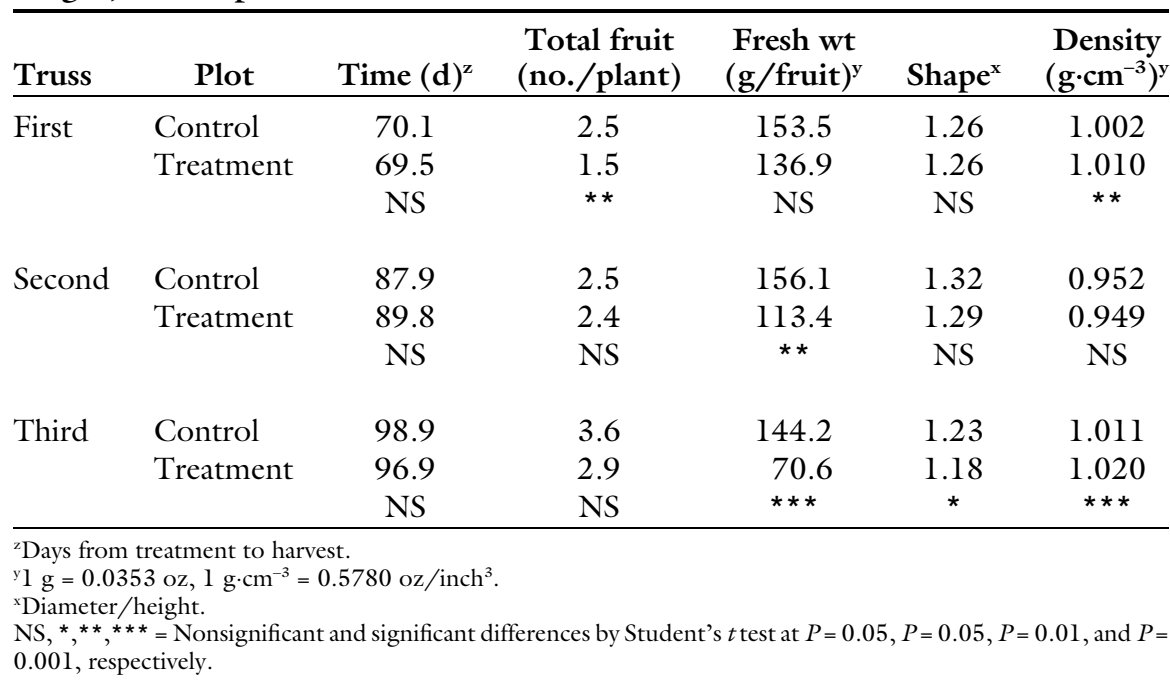

Table 3. Effect of basal wire coiling treatment on sugar, acid, and soluble solids concentrations of juices made from marketable tomato fruit.

\begin{tabular}{|c|c|c|c|c|c|c|c|c|}
\hline Truss & Plot & $\begin{array}{c}\text { Sucrose } \\
(\%)\end{array}$ & $\begin{array}{c}\text { Glucose } \\
(\%)\end{array}$ & $\begin{array}{c}\text { Fructose } \\
(\%)\end{array}$ & $\begin{array}{c}\text { Oxalic } \\
\text { acid } \\
(\%)\end{array}$ & $\begin{array}{c}\text { Citric } \\
\text { acid } \\
(\%) \\
\end{array}$ & $\begin{array}{c}\text { Malic } \\
\text { acid } \\
(\%) \\
\end{array}$ & $\begin{array}{c}\text { Soluble } \\
\text { solids } \\
(\%) \\
\end{array}$ \\
\hline \multirow[t]{3}{*}{ First } & Control & 0.08 & 1.06 & 1.12 & 0.015 & 0.955 & 0.061 & 6.9 \\
\hline & Treatment & 0.21 & 1.48 & 1.57 & 0.010 & 1.060 & 0.061 & 8.3 \\
\hline & & ** & $* * *$ & $* * *$ & NS & ** & NS & $* * *$ \\
\hline \multirow[t]{3}{*}{ Second } & Control & 0.06 & 1.25 & 1.29 & 0.009 & 1.028 & 0.051 & 7.6 \\
\hline & Treatment & 0.29 & 1.90 & 2.00 & 0.016 & 1.201 & 0.053 & 8.9 \\
\hline & & ** & $* * *$ & $* * *$ & NS & ** & NS & $* * *$ \\
\hline \multirow[t]{3}{*}{ Third } & Control & 0.08 & 1.38 & 1.37 & 0.009 & 1.083 & 0.046 & 7.9 \\
\hline & Treatment & 0.28 & 1.86 & 1.94 & 0.011 & 1.241 & 0.051 & 9.2 \\
\hline & & $\star * *$ & $* * *$ & $* * *$ & ** & $* *$ & NS & $* * *$ \\
\hline
\end{tabular}

NS, ${ }^{* *},{ }^{* *}=$ Nonsignificant and significant differences by Student's $t$ test at $P=0.05, P=0.01$, and $P=0.001$ respectively. coiling on the sugar and organic acid concentrations of juice made from the harvested fruit. Williams and Bevenue (1954) analyzed the juice from crushed ripe tomatoes for sugars; Sakiyama (1966) analyzed tomato juice for organic acids; and Baldwin et al. (1991) and Simandle et al. (1966) analyzed the tomato juice for both sugars and organic acids. As reported by these authors and replicated by our results, fructose and glucose were the main sugar components of tomato juice, and citric acid is the main organic acid.

The total soluble solids concentrations were higher (116\% to $120 \%$ ) in the juices of fruit from the first to third trusses of the treated plants compared with those from the corresponding trusses of control plants. The sugar concentrations were higher in the juices from the treated plants than in those from the control plants (263\% to $483 \%$ higher for sucrose and $135 \%$ to $155 \%$ higher for fructose and glucose). In addition, the citric acid concentrations were higher ( $111 \%$ to $117 \%)$ in the juices of fruit from all three trusses of treated plants compared with those from the control plants. The results show that basal wire coiling brought about smaller increases in the organic acid concentrations than in the sugar concentrations. As the data show, basal wire coiling markedly increased the soluble solids, fructose, and glucose concentrations in the tomato fruit juice.

Other types of treatments have increased the concentrations of sugars and other components in tomatoes. Ehret and Ho (1986) increased the salt concentration of a nutrient solution and found increases in the dry matter percentages of fruit from plants grown in the solution. Saito et al. (2009) and Sakamoto et al. (1999) found that the soluble solids concentration increased in the fruit of plants subjected to salt stress. Johnstone et al. (2005) and Rudich et al. (1977) reduced the amount of watering and found increased soluble solids concentration.

In plants other than tomato, Greene (1937) reported that girdling the basal regions of branches resulted in increased dry matter percentage in the apple fruit (including flowers) of spurs extending from the branches.

Salt and water stresses influence water levels in the root sphere and 
suppress water absorption by the roots. Since basal wire coiling in this experiment markedly suppressed root growth, presumably by impeding photosynthate translocation through the phloem to the roots, we assume that water absorption was also decreased by this treatment. Furthermore, impeding water transport through the xylem to the upper parts of the plant by this treatment should accelerate a reduction in the moisture content of the shoot. Sitton (1949) selected 5 -year-old fruit trees, indicating that the roots had sufficiently grown, and girdled the basal regions of some branches extending from a trunk. Therefore, girdling does not strongly suppress water absorption by the roots. In addition, girdling does not impede water transport. Because stem and node growth were also suppressed, basal wire coiling appears to have decreased the total amount of photosynthate produced per plant; however, the decrease in moisture content conceivably was greater than the decrease in photosynthate production, as suggested by the increased concentrations of sugars and other components in the fruit juice. The increased fruit dry matter percentage resulting from salt stress (Ehret and Ho, 1986) was also explained by a similar relationship between water and dry matter. Saito et al. (2009) showed the involvement of activated sugar translocation to fruit by increased enzymatic hydrolysis of sucrose in fruit under salt stress conditions. Basal wire coiling may also have reduced competition for photosynthates between fruit and roots. We hypothesize that the decrease in moisture content, minor decrease in photosynthate production, activated sugar translocation, and reduced competition for photosynthates resulting from basal wire coiling could be responsible for the increase in the sugar concentrations in tomato fruit juice.

Treatments such as subjecting tomato plants to salt or water stress require special equipment and techniques. In contrast, the treatment described in this study involves simply coiling wire around the basal regions of seedling stems. The practical application of basal wire coiling to tomato culture will require further investigations, e.g., to identify the appropriate location and time for coiling plants with wire, to identify the optimum width of the wire coil, to optimize methods for nutrient and water management, to monitor the yields and quality of fruit produced by this method, and to calculate the economic impacts for producers and consumers. It will also be important to determine the extent of blossom-end rot that occurs when applying this treatment and to investigate methods for controlling this disorder if necessary.

\section{Literature cited}

Baldwin, E.A., M.O. Nisperos-Carriedo, and M.G. Moshonas. 1991. Quantitative analysis of flavor and other volatiles and for certain constituents of two tomato cultivars during ripening. J. Amer. Soc. Hort. Sci. 1 16:265-269.

Ehret, D.L. and L.C. Ho. 1986. The effects of salinity on dry matter partitioning and fruit growth in tomatoes grown in nutrient film culture. J. Hort. Sci. 61:361-367.

Greene, L. 1937. Ringing and fruit setting as related to nitrogen and carbohydrate content of Grimes Golden apples. J. Agr. Res. 54:863-875.

Johnstone, P.R., T.K. Hartz, M. LeStrange, J.J. Nunez, and E.M. Miyao. 2005. Managing fruit soluble solids with late-season deficit irrigation in drip-irrigated processing tomato production. HortScience 40:1857-1861
Mason, T.G. and E.J. Maskell. 1928. Studies on the transport of carbohydrates in the cotton plant. 1. A study of diurnal variation in the carbohydrates of leaf, bark, and wood, and of the effects of ringing. Ann. Bot. (Lond.) 57:189253.

Noel, A.R.A. 1970. The girdled tree. Bot. Rev. 36:162-195.

Richardson, M. 1975. Translocation in plants. 2nd ed. Edward Arnold, London, UK.

Rudich, J., D. Kalmar, C. Geizenberg, and S. Harel. 1977. Low water tensions in defined growth stages of processing tomato plants and their effects on yield and quality. J. Hort. Sci. 52:391-399.

Saito, T., N. Fukuda, C. Matsukura, and S. Nishimura. 2009. Effects of salinity on distribution of photosynthates and carbohydrate metabolism in tomato growth using nutrient film technique. J. Jpn. Soc. Hort. Sci. 78:90-96.

Sakamoto, Y., S. Watanabe, T. Nakashima, and K. Okano. 1999. Effects of salinity at two ripening stages on the fruit quality of single-truss tomato grown in hydroponics. J. Hort. Sci. Biotechnol. 74:690693.

Sakiyama, R. 1966. Changes in acid contents of tomato fruits during development. J. Jpn. Soc. Hort. Sci. 35:36-42.

Simandle, P.A., J.L. Brogdon, J.P. Sweeney, E.O. Mobley, and D.W. Davis. 1966. Quality of six tomato varieties as affected by some compositional factors. Proc. Amer. Soc. Hort. Sci. 89:532-538.

Sitton, B.G. 1949. The effects of different methods of girdling bearing and defruited tung branches. Proc. Amer. Soc. Hort. Sci. 53:119-124.

Williams, K.T. and A. Bevenue. 1954. Vegetable components, some carbohydrate components of tomato. J. Agr. Food Chem. 2:472-474. 